\title{
EDITORIAL
}

\section{Superoxide dismutase: Master and Commander?}

\author{
E.K. Weir*, Z. Hong ${ }^{\#}$ and Y. Chen*
}

I nhaled nitric oxide (NO) has long been known to be an effective pulmonary vasodilator in the normal pulmonary vasculature. In the classical NO signalling pathway, it activates soluble guanylate cyclase in the cytoplasm of pulmonary artery smooth muscle cells, leading to the production of cyclic guanosine monophosphate (cGMP), which then activates protein kinase G (PKG). PKG, acting through several downstream targets, causes vasodilatation. In addition, NO acts through induction of post-translational changes, such as $S$ nitrosylation of proteins with reactive thiols. NO levels are decreased in idiopathic pulmonary arterial hypertension (IPAH) [1, 2], in patients with PAH secondary to anorectic agents [3] and in infants with persistent pulmonary hypertension of the newborn (PPHN) [4]. In part, NO is decreased because of the reduced endothelial NO synthase (eNOS) that has been reported in PAH and in PPHN $[5,6]$. More recently, an additional mechanism has been described. Asymmetric dimethylarginine (ADMA) is an endogenous inhibitor of nitric oxide synthase and IPAH patients have increased levels of ADMA in their blood and lungs [7]. ADMA is metabolised by dimethylarginine dimethylaminohydrolase (DDAH) 1 or DDAH2, two enzymes encoded by different genes. Although solid evidence supporting a role for DDAH2 in the degradation of lung ADMA is not available, DDAH1 gene deletion in vascular endothelial cells causes accumulation of ADMA in the lung tissue of mice [8]. Similarly, monocrotaline injection causes a decrease in lung DDAH1 expression and DDAH activity, leading to the accumulation of ADMA in rats, which may then contribute to the development of pulmonary hypertension [9]. The increased ADMA levels provide another mechanism to explain the decreased NO levels in PAH. It is also worth noting that in IPAH patients, higher ADMA plasma levels correlate with worse pulmonary haemodynamics and decreased survival [7].

Given the reduced level of NO in PAH, it is not surprising that efforts have been made to increase endogenous NO production. Endothelial NO synthetase generates NO through the oxidation of L-arginine, using tetrahydrobiopterin $\left(\mathrm{BH}_{4}\right)$, oxygen, nicotinamide adenine dinucleotide phosphate (NADPH) and calcium/calmodulin as cofactors. Decreased availability of L-arginine or $\mathrm{BH}_{4}$ can lead to uncoupling of NOS and production of superoxide anion $\left(\mathrm{O}_{2}^{-}\right) \cdot \mathrm{O}_{2}^{-}$production can also be increased in the lung through other mechanisms, such as $\mathrm{NAD}(\mathrm{P}) \mathrm{H}$ oxidase activity or mitochondrial metabolism.

*Dept of Medicine, University of Minnesota, Minneapolis, MN, and *Dept of Medicine, University of Chicago, Chicago, IL, USA.

CORRESPONDENCE: E.K. Weir, VA Medical Center, One Veterans Drive, Minneapolis, MN 55417, USA. E-mail: weirx002@umn.edu
$\mathrm{O}_{2}^{-}$in turn, can combine with $\mathrm{NO}$ to form peroxynitrite or, through the action of one of three classes of superoxide dismutase (SOD), generate hydrogen peroxide $\left(\mathrm{H}_{2} \mathrm{O}_{2}\right)$. Supplementation of L-arginine, either by intravenous infusion for $30 \mathrm{~min} \mathrm{[10]} \mathrm{or} \mathrm{orally} \mathrm{for} \mathrm{a} \mathrm{week} \mathrm{[11],} \mathrm{produces} \mathrm{modest}$ decreases in pulmonary artery pressure (16 and $9 \%$, respectively) and resistance (28 and 16\%, respectively).

Production of $\mathrm{BH}_{4}$ requires the activity of GTP-cyclohydrolase 1 (GTP-CH1). The hyperphenylalaninemic mouse (hph-1) has a $90 \%$ reduction in GPT-CH1 activity, decreased NO levels and develops pulmonary hypertension, even under normoxic circumstances [12]. These mice have a marked increase in $\mathrm{O}_{2}$ production in the lungs [13]. When hph-1 mice are crossed with mice that overexpress GTP-CH1 to increase $\mathrm{BH}_{4}$ synthesis, the progeny have increased NOS activity and decreased $\mathrm{O}_{2}{ }^{-}$in the lungs. They do not develop normoxic pulmonary hypertension [13]. In an elegant paper in this issue of the European Respiratory Journal (ERJ), FRANCIS et al. [14] examine the role of $\mathrm{BH}_{4}$ in altering the severity of hypoxic pulmonary vasoconstriction (HPV) in isolated rat and mouse lungs [14]. They show that the addition of $\mathrm{BH}_{4}$ to the perfusate of the rat lungs increased nitrate/nitrite levels and reduced HPV. Similar effects of $\mathrm{BH}_{4}$ on HPV were observed in wild-type mouse lungs. This would be predictable based on increased NO production. However, there are two additional parts of the $\mathrm{BH}_{4}$ inhibition of HPV. One is the finding that an SOD mimetic (MnTMPyP) increased the vasodilator effect of $\mathrm{BH}_{4}$. This, and a reduction in HPV achieved by the antioxidant $\mathrm{NH}_{4}$, which is not a NOS co-factor, indicate that $\mathrm{O}_{2}{ }^{-}$, or radicals downstream, such as peroxynitrite or hydroxyl radical, were contributing to the vasoconstriction. The other component that was identified was a dilatory effect of $\mathrm{H}_{2} \mathrm{O}_{2}$, based on the observation that catalase diminished the $\mathrm{BH}_{4}$ inhibition of HPV. This effect of $\mathrm{H}_{2} \mathrm{O}_{2}$ would be concordant with its proposed pulmonary vasodilator effect [15-17]. The vasodilatation may occur as a result of stimulation of guanylate cyclase, associated with the reduction of $\mathrm{H}_{2} \mathrm{O}_{2}$ by catalase or changes in $\mathrm{NAD}(\mathrm{P}) \mathrm{H}$ redox status [18]. It is also known that proteins containing deprotonated cysteine residues can be oxidised by $\mathrm{H}_{2} \mathrm{O}_{2}$. Several phosphatases are inactivated by this mechanism, prolonging phosphorylation in signalling pathways.

One important point to note is that, although $\mathrm{O}_{2}^{-}$and $\mathrm{H}_{2} \mathrm{O}_{2}$ both cause oxidation, $\mathrm{O}_{2}{ }^{-}$causes vasoconstriction in this $\mathrm{BH}_{4}$ model, while $\mathrm{H}_{2} \mathrm{O}_{2}$ causes vasodilatation. Consequently it is their specific molecular interactions or the microlocation within the cell that determines the outcome. The variety of SODs ( $\mathrm{Cu} \mathrm{Zn}, \mathrm{Mn}$, extracellular) and peroxidases (gluthathione peroxidase, catalase, peroxiredoxin, thioredoxin) may determine where and how oxidation occurs and what signals are 
relayed [19]. For instance, $\mathrm{O}_{2}^{-}$causes oxidation of many proteins but not protein-tyrosine phosphatase 1B (PTP1B), which is oxidised and inhibited by $\mathrm{H}_{2} \mathrm{O}_{2}$ [20]. Given that $\mathrm{BH}_{4}$ stimulates the production of $\mathrm{NO}, \mathrm{O}_{2}{ }^{-}, \mathrm{H}_{2} \mathrm{O}_{2}$ and a variety of radicals derived from their interaction, the role of the SODs, controlling the watershed between $\mathrm{O}_{2}^{-}$and $\mathrm{H}_{2} \mathrm{O}_{2}$ is critically important. Inhibition of, or decreased expression of, SOD leading to higher $\mathrm{O}_{2}^{-}$levels increases oxidative damage [21], while in the setting of HPV, the use of an SOD mimetic (decreasing $\mathrm{O}_{2}^{-}$and increasing $\mathrm{H}_{2} \mathrm{O}_{2}$ ) abolishes HPV in the isolated rat lung [22]. Similarly, in a model of persistent PPHN in the lamb, ATP causes constriction of pulmonary artery rings [23] but in the presence of an SOD mimetic, ATP causes dosedependent relaxation. It is not clear how much the $\mathrm{O}_{2}{ }^{-}$effect impaired ATP-induced vasodilatation and how much $\mathrm{H}_{2} \mathrm{O}_{2}$ contributed to it. In the paper in this issue of the ERJ [14], the SOD mimetic did not alter HPV; however, catalase increased HPV in hph-1 mice and heterozygotes, and tended to increase it in the wild-type mice. This suggests a vasodilator role for $\mathrm{H}_{2} \mathrm{O}_{2}$ in the setting of HPV, a concept proposed in 1986 [24] and supported by recent observations in bovine pulmonary arteries [25].

The activity of SOD becomes even more interesting when its role in PAH is considered. Mitochondrial SOD is decreased in the pulmonary artery smooth muscle cells of IPAH patients and fawn-hooded rats [26]. The latter spontaneously develop pulmonary hypertension. The use of an SOD mimetic in rats exposed to chronic hypoxia prevents pulmonary hypertension and reduces right ventricular hypertrophy, suggesting that the observed decrease in SOD in IPAH patients may play a role in the aetiology [27]. These findings are supported by observations made in PPHN lambs, which have decreased SOD. Intralobar pulmonary arteries taken from such lambs, ventilated with $100 \% \mathrm{O}_{2}$, show markedly increased contraction to norepinephrine [28]. A single dose of recombinant human SOD (rhSOD), given intratracheally at the time of delivery, reduces the norepinephrine contraction to the levels seen in control lambs. The one dose of rhSOD also increased the activity of GTP-CH1, the rate-limiting enzyme in the synthesis of $\mathrm{BH}_{4}$, and levels of $\mathrm{BH}_{4}$ in the lungs.

FRANCIS et al. [14] suggest consideration of $\mathrm{BH}_{4}$ administration in the treatment of pulmonary hypertension. A large number of studies indicate that $\mathrm{BH}_{4}$ improves systemic vascular endothelial function in patients with hypertension, hypercholesterolaemia, heart failure, coronary artery disease, old age and in smokers [29]. From the discussion here, it seems that $\mathrm{BH}_{4}$ is a Jekyll and Hyde intervention, with $\mathrm{O}_{2}{ }^{-}$playing the part of the evil Mr Hyde and $\mathrm{NO}$ and $\mathrm{H}_{2} \mathrm{O}_{2}$ acting in concert as the benevolent Dr Jekyll. However, the most important role is that of the stage director, superoxide dismutase, who determines whether good or ill will predominate. Administration of $\mathrm{BH}_{4}$ in conjunction with SOD may be the best therapy to test in the long-term treatment of pulmonary hypertension.

\section{SUPPORT STATEMENT}

E.K Weir is suppored by a National Heart, Lung and Blood Institute grant RO1 HL-65322.

\section{STATEMENT OF INTEREST}

None declared.

\section{REFERENCES}

1 Girgis R, Champion H, Diette G, et al. Decreased exhaled nitric oxide in pulmonary aterial hypertension: response to bosentan therapy. Am J Respir Crit Care Med 2005; 172: 262-263.

2 Demoncheaux E, Higenbottam T, Kiely D, et al. Decreased whole body endogenous nitric oxide production in patients with primary pulmonary hypertension. J Vasc Res 2005; 42: 133-136.

3 Archer S, Djaballah K, Humbert M, et al. Nitric oxide deficiency in fenfluramine- and dexfenfluramine- induced pulmonary hypertension. Am J Respir Crit Care Med 1998; 158: 1061-1067.

4 Dollberg S, Warner B, Myatt L. Urinary nitrite and nitrate concentrations in patients with idiopathic persistent pulmonary hypertension of the newborn and effect of extracorporeal membrane oxygenation. Pediatr Res 1995; 36: 31-34.

5 Giaid A, Saleh D. Reduced expression of endothelial nitric oxide synthase in the lungs of patients with pulmonary hypertension. N Engl J Med 1995; 333: 214-221.

6 Villanueva M, Zaher F, Svinarich D, et al. Decreased gene expression of endothelial nitric oxide synthase in newborns with persistent pulmonary hypertension. Pediatr Res 1998; 44: 337-343.

7 Kielstein J, Bode-Böger S, Hesse G, et al. Asymmetrical dimethylarginine in idiopathic pulmonary arterial hypertension. Arterioscler Thromb Vasc Biol 2005; 25: 1414-1418.

$8 \mathrm{Hu} \mathrm{X}, \mathrm{Xu} \mathrm{X}$, Zhu G, et al. Vascular endothelial-specific dimethylarginine dimethlyaminohydrolase-1 -deficient mice reveal that vascular endothelium plays an important role in removing asymmetric dimethylarginine. Circulation 2009; 120: 2222-2229.

9 Sasaki A, Doi S, Mizutani S, et al. Roles of accumulated endogenous nitric oxide synthase inhibitors, enhanced arginase activity, and attenuated nitric oxide synthase activity in endothelial cells for pulmonary hypertension in rats. Am J Physiol Lung Cell Mol Physiol 2007; 292: L1480-1487.

10 Mehta S, Stewart D, Langleben D, et al. Short-term pulmonary vasodilation with L-arginine in pulmonary hypertension. Circulation 1995; 92: 1539-1545.

11 Nagaya N, Uematsu M, Oya H, et al. Short-term oral administration of L-arginine improves hemodynamics and exercise capacity in patients with precapillary pulmonary hypertension. Am J Respir Crit Care Med 2001; 163: 887-891.

12 Nandi M, Miller A, Stidwill R, et al. Pulmonary hypertension in a GTP-cyclohydrolase 1-deficient mouse. Circulation 2005; 111 2086-2090.

13 Khoo J, Zhao L, Alp N, et al. Pivotal role for endothelial tetrahydrobiopterin in pulmonary hypertension. Circulation 2005; 111: 2126-2133.

14 Francis BN, Wilkins MR, Zhao L. Tetrahydrobiopterin and the regulation of hypoxic pulmonay vasoconstriction. Eur Respir J 2010; 36: 323-330.

15 Mohazzab-H K, Wolin M. Oxidant signalling and vascular oxygen sensing. Role of $\mathrm{H}_{2} \mathrm{O}_{2}$ in responses of the bovine pulmonary artery to changes in $\mathrm{PO}_{2}$. In: Lahiri S, ed. Oxygen Sensing: Molecule to Man. New York, Kluwer Academic/Plenum Publishers, 2000; pp. 249-258.

16 Michelakis E, Hampl V, Nsair A, et al. Diversity in mitochodrial function explains differences in vascular oxygen sensing. Circ Res 2002; 90: 1307-1315.

17 Weir E, Lopez-Barneo J, Buckler K, et al. Acute oxygen-sensing mechanisms. N Engl J Med 2005; 353: 2042-2055.

18 Wolin M. Reactive oxygen species and the control of vascular function. Am J Physiol Heart Circ Physiol 2009; 296: H539-H549.

19 Veal E, Day A, Morgan B. Hydrogen peroxide sensing and signaling. Molecular Cell 2007; 26: 1-14.

20 Juarez J, Manuia $M$, Burnett $M$, et al. Superoxide dismutase 1 (SOD1) is essential for $\mathrm{H}_{2} \mathrm{O}_{2}$-mediates oxidation and inactivation 
of phosphatases in growth factor signaling. PNAS 2008; 105: 7147-7152.

21 Williams M, Van Remmen H, Conrad C, et al. Increased oxidative damage is correlated to altered mitochondrial function in heterozygous manganase superoxide dismutase knockout mice. J Biol Chem 1998; 273: 28510-28515.

22 Hodyc D, Snorek M, Brtnicky T, et al. Superoxide dismutase mimetic tempol inhibits hypoxic pulmonary vasoconstriction in rats independently of nitric oxide production. Exp Physiol 2007; 92: 945-951.

23 Konduri G, Bakhutashvili I, Els A, et al. Oxidant stress from uncoupled nitric oxide synthase impairs vasodilation in fetal lambs with persistent pulmonary hypertension. Am J Physiol Heart Circ Physiol 2007; 292: H1812-H1820.

24 Archer S, Will J, Weir E. Redox status in the control of pulmonary vascular tone. Herz 1986; 11: 127-141.

25 Ahmad M, Zhao X, Kelly M, et al. Heme oxygenase- 1 induction modulates hypoxic pulmonary vasoconstriction through upregulation of ecSOD. Am J Physiol Heart Circ Physiol 2009; 297: H1453-H1461.

26 Bonnet S, Michelakis E, Porter C, et al. An abnormal mitochondrial-hypoxia inducible factor- $1 \alpha-\mathrm{Kv}$ channel pathway disrupts oxygen sensing and triggers pulmonary arterial hypertension in fawn hooded rats. Similiarities to human pulmonary arterial hypertension. Circulation 2006; 113: 2630-2641.

27 Elmedal B, de Dam M, Mulvany M, et al. The superoxide disutase mimetic, tempol, blunts right ventricular hypertrophy in chronic hypoxic rats. Br J Pharmacol 2004; 141: 105-113.

28 Farrow K, Lakshminrusimha S, Reda WJ, et al. Superoxide dismutase restores eNOS expression and function in resistance pulmonary arteries from neonatal lambs with persistent pulmonary hypertension. Am J Physiol Lung Cell Mol Physiol 2008; 295: L979-L987.

29 Katusic Z, d'Uscio L, Nath K. Vascular protection by tetrahydrobiopterin: progress and therapeutic prospects. Trends Pharmacol Sci 2009; 39: 48-54. 